\title{
Human genetic evidence supports MAP3K15 inhibition as a therapeutic strategy for diabetes
}

Abhishek Nag ${ }^{1 *}$, Ryan S. Dhindsa ${ }^{2 *}$, Andrew R. Harper ${ }^{1}$, Dimitrios Vitsios ${ }^{1}$, Andrea Ahnmark ${ }^{3}$, Bilada Bilican ${ }^{4}$, Katja Madeyski-Bengtson ${ }^{4}$, Bader Zarrouki ${ }^{3}$, Quanli Wang ${ }^{2}$, Katherine Smith ${ }^{1}$, Dave Smith ${ }^{5}$, Benjamin Challis ${ }^{6}$, Dirk S. Paul ${ }^{1}$, Mohammad Bohlooly-Y $Y^{4}$, Mike Snowden ${ }^{7}$, David Baker ${ }^{8}$, Regina Fritsche-Danielson ${ }^{9}$, Menelas N. Pangalos ${ }^{10}$, Slavé Petrovski ${ }^{1,11}$

${ }^{1}$ Centre for Genomics Research, Discovery Sciences, BioPharmaceuticals R\&D, AstraZeneca, Cambridge, UK

${ }^{2}$ Centre for Genomics Research, Discovery Sciences, BioPharmaceuticals R\&D, AstraZeneca, Waltham, USA

${ }^{3}$ Bioscience Metabolism, Early CVRM, BioPharmaceuticals R\&D, AstraZeneca, Gothenburg, Sweden

${ }^{4}$ Discovery Biology, Discovery Sciences, BioPharmaceuticals R\&D, AstraZeneca, Gothenburg, Sweden

${ }^{5}$ Emerging Innovations, Discovery Sciences, BioPharmaceuticals R\&D, AstraZeneca, Cambridge, UK

${ }^{6}$ Translational Science and Experimental Medicine, Early CVRM, BioPharmaceuticals R\&D, AstraZeneca, Cambridge, UK

${ }^{7}$ Discovery Sciences, BioPharmaceuticals R\&D, AstraZeneca, Cambridge, UK

${ }^{8}$ Bioscience Metabolism, Early CVRM, BioPharmaceuticals R\&D, AstraZeneca, Cambridge, UK

${ }^{9}$ Early CVRM, BioPharmaceuticals R\&D, AstraZeneca, Gothenburg, Sweden

${ }^{10}$ BioPharmaceuticals R\&D, AstraZeneca, Cambridge, UK

${ }^{11}$ Departments of Medicine and Neurology, University of Melbourne, Royal Melbourne Hospital, Melbourne, Victoria, Australia

*These authors contributed equally

\section{Corresponding author:}

Slavé Petrovski

Vice-President, Centre for Genomics Research,

Discovery Sciences, BioPharmaceuticals R\&D

AstraZeneca

Cambridge

United Kingdom

Email: slav.petrovski@astrazeneca.com

NOTE: This preprint reports new research that has not been certified by peer review and should not be used to guide clinical practice. 
medRxiv preprint doi: https://doi.org/10.1101/2021.11.14.21266328; this version posted November 15, 2021. The copyright holder for this preprint (which was not certified by peer review) is the author/funder, who has granted medRxiv a license to display the preprint in

\section{Abstract}

2 Diabetes mellitus is a chronic health condition that can result in significant end-organ 3 complications and is estimated to impact at least $8.5 \%$ of the global adult population. Here, 4 we performed gene-level collapsing analysis on exome sequences from 454,796 multi5 ancestry UK Biobank participants to detect genetic associations with diabetes. Rare non6 synonymous variants in GCK, GIGYF1, HNF1A, and HNF4A were significantly associated $7 \quad\left(P<1 \times 10^{-8}\right)$ with increased risk of diabetes, whereas rare non-synonymous variants in 8 MAP3K15 were significantly associated with reduced risk of diabetes. Recessive carriers of 9 rare non-synonymous variants in the $\mathrm{X}$ chromosome gene MAP3K15 had a $30 \%$ reduced risk 10 of diabetes $\left(\mathrm{OR}=0.70,95 \% \mathrm{Cl}\right.$ : $\left.[0.62,0.79], P=5.7 \times 10^{-10}\right)$, along with reduced blood glucose 11 (beta $\left.=-0.13,95 \% \mathrm{Cl}:[-0.15,-0.10], P=5.5 \times 10^{-18}\right)$ and reduced glycosylated haemoglobin levels 12 (beta $\left.=-0.14,95 \% \mathrm{Cl}:[-0.16,-0.11], P=1.1 \times 10^{-24}\right)$. Hemizygous males carrying protein13 truncating variants (PTVs) in MAP3K15 demonstrated a $40 \%$ reduced risk of diabetes $14(\mathrm{OR}=0.60,95 \% \mathrm{Cl}$ : [0.45,0.81], $P=0.0007)$. These findings were independently replicated in 15 FinnGen, with a MAP3K15 PTV associating with decreased risk of both type 1 diabetes 16 (T1DM) and type 2 diabetes (T2DM) ( $p<0.05)$. The effect of MAP3K15 loss on diabetes was 17 independent of body mass index, suggesting its protective effect is unlikely to be mediated via 18 the insulin resistance pathway. Tissue expression profile of MAP3K15 indicates a possible 19 involvement of pancreatic islet cell or stress response pathways. No safety concerns were 20 identified among heterozygous or recessive MAP3K15 PTV carriers across over 15,719 21 studied endpoints in the UK Biobank. Human population genetic evidence supports MAP3K15 22 inhibition as a novel therapeutic target for diabetes. 
medRxiv preprint doi: https://doi.org/10.1101/2021.11.14.21266328; this version posted November 15,2021 . The copyright holder for this preprint (which was not certified by peer review) is the author/funder, who has granted medRxiv a license to display the preprint in

It is made available under a CC-BY-NC-ND 4.0 International license.

\section{Introduction}

24 Diabetes mellitus is a worldwide health concern projected to affect 700 million people by

$252045^{1}$. It is currently the leading cause of micro- and macrovascular disease, including kidney

26 failure, blindness, heart disease, and lower limb amputations ${ }^{2}$. Characterized by elevated

27 levels of blood glucose, diabetes mellitus is generally categorised into type 1 diabetes mellitus

28 (T1DM), type 2 diabetes mellitus (T2DM), and other rarer forms. T1DM is caused by

29 autoimmune destruction of insulin-producing pancreatic $\beta$-cells, while T2DM is primarily

30 caused by peripheral insulin resistance. Both types of diabetes eventually lead to progressive

31 loss of pancreatic $\beta$-cells and deficient insulin secretion.

32 Genome wide association studies (GWAS) have implicated over 60 loci in T1DM ${ }^{3}$ and

33 many hundreds of loci in $\mathrm{T}_{2} \mathrm{DM}^{4,5}$. Except for a few loci that map to protein-coding regions

34 (e.g., $P A M)^{4}$, the majority reside in non-coding regions of the genome, making it challenging

35 to map the candidate gene and characterise the underlying causal biology. The growing

36 availability of whole-exome sequences in large population-scale biobanks offers

37 unprecedented opportunities to identify protein-coding variants that have demonstrably large

38 effects on human traits and thus potentially constitute more clinically efficacious target

39 opportunities ${ }^{6}$. Identifying loss-of-function variants that protect against disease is of particular

40 interest since these discoveries can provide direct human-validated therapeutic targets ${ }^{7-9}$.

41 Here, we report a multi-ancestry exome-sequencing association study for diabetes in

42412,394 exomes from the UK Biobank (UKB). Using our previously described gene-level

43 collapsing framework ${ }^{10}$, we identified that recessive loss of the $\mathrm{X}$ chromosome gene MAP3K15

44 was associated with $40 \%$ reduced risk of developing diabetes and decreased circulating

45 glucose and haemoglobin A1c levels. The findings were replicated in the FinnGen study, with

46 a PTV in MAP3K15 associating with decreased risk of both T1DM and T2DM. Furthermore,

47 the loss of MAP $3 K 15$ was not associated with any apparent on-target adverse phenotypes in

48 a phenome-wide assessment of 15,719 clinical endpoints, supporting MAP3K15 as a

49 potentially safe target for selective therapeutic inhibition. 
medRxiv preprint doi: https://doi.org/10.1101/2021.11.14.21266328; this version posted November 15,2021 . The copyright holder for this preprint (which was not certified by peer review) is the author/funder, who has granted medRxiv a license to display the preprint in It is made available under a CC-BY-NC-ND 4.0 International license .

Results

\section{Cohort characteristics and study design}

52 We processed exome sequences from 454,796 UKB participants through our previously described cloud-based pipeline ${ }^{10}$. Through stringent quality control, we removed samples with low sequencing quality, low depth of coverage, and from closely related individuals (Methods). For this study, we focused on 90 binary clinical phenotypes related to T1DM and T2DM available in the UKB (Supplementary Table 1A). In total, there were 39,044 cases that mapped to at least one of the diabetes-related clinical phenotypes, including 35,035 of European ancestry, 2,262 of South Asian ancestry, 249 of East Asian ancestry, and 1,498 of African ancestry. Measurements for quantitative traits related to diabetes, including blood glucose, glycosylated haemoglobin ( $\mathrm{HbA1c}$ ), and body mass index (BMI), were also available for participants (Supplementary Table 1B).

We employed a gene-level collapsing framework to test the aggregate effect of rare non-synonymous variants in each gene $(N=18,762)$ against each of the diabetes-related clinical phenotypes (Methods). Each gene-phenotype combination was tested under 10 nonsynonymous collapsing models (including one recessive model) to evaluate a range of genetic architectures, as previously described ${ }^{10}$ (Supplementary Table 2). We performed two versions of the collapsing analysis: one restricted to individuals of European ancestry and the other a pan-ancestry analysis, as previously described ${ }^{10}$ (Methods). No inflation of test statistics was observed in the gene-level collapsing analysis for the 90 diabetes-related clinical phenotypes that were tested (median genomic inflation lambda across all models $=1.01$ ).

Rare-variant collapsing analysis

We identified four protein-coding genes significantly associated $\left(P<1 \times 10^{-8}\right)$ with at least one diabetes-related clinical phenotype in the European-only analysis (Figure 1A; Table 1; Supplementary Table 3). Rare non-synonymous variants in GCK, GIGYF1, and HNF1A were associated with increased risk of diabetes, whereas rare non-synonymous variants in MAP3K15 were associated with reduced risk of diabetes. In the pan-ancestry analysis, all four of these genes maintained statistical significance; one additional gene, HNF4A, that was associated with increased risk of diabetes, achieved significance in the pan-ancestry analysis (Supplementary Table 4).

In our phenome-wide association study of 269,171 European UKB participants ${ }^{10}$, the recessive collapsing model, which includes homozygous, hemizygous, and putative compound heterozygous carriers of rare non-synonymous variants, identified unequivocal associations $\left(P<1 \times 10^{-8}\right)$ between MAP3K15 and reduced haemoglobin $\mathrm{A} 1 \mathrm{C}(\mathrm{HbA} 1 \mathrm{c})$ and 
medRxiv preprint doi: https://doi.org/10.1101/2021.11.14.21266328; this version posted November 15,2021 . The copyright holder for this preprint (which was not certified by peer review) is the author/funder, who has granted medRxiv a license to display the preprint in It is made available under a CC-BY-NC-ND 4.0 International license .

participants ${ }^{11}$ also found suggestive association between MAP3K15 and T2DM (OR $=0.85, P$ $=2.8 \times 10^{-6}$ ) under an additive genetic model. Among common variant literature, an intronic variant in MAP3K15 was one of over 300 novel loci reported in a large trans-ethnic GWAS of $\mathrm{T}_{2} \mathrm{DM}^{5}\left(\mathrm{OR}=1.14, P=1.4 \times 10^{-8}\right)$. In this current study, with an increased sample size of 394,695 European participants, the association between MAP3K15 and diabetes reached study-wide significance $\left(\mathrm{p}<1 \times 10^{-8}\right)$ in the recessive model $(\mathrm{OR}=0.70 ; 95 \% \mathrm{Cl}:[0.62,0.79], P$ $\left.=5.0 \times 10^{-9}\right)$. Consistent with our prior findings, the MAP3K15 qualifying variant $(\mathrm{QV})$ carriers had significantly lower $\mathrm{HbA} 1 \mathrm{c}$ levels (beta $=-0.14,95 \% \mathrm{Cl}$ : $[-0.16,-0.11], P=3.1 \times 10^{-23}$ ) (Figure 1B) and blood glucose levels (beta $=-0.13,95 \% \mathrm{Cl}$ : $[-0.16,-0.10], P=2.5 \times 10^{-17}$ ). In our panancestry analysis, the associations became more significant between MAP $3 K 15$ recessive variants and diabetes $\left(\mathrm{OR}=0.70,95 \% \mathrm{Cl}:[0.62,0.79], P=5.7 \times 10^{-10}\right), \mathrm{HbA} 1 \mathrm{c}$ (beta $=-0.14$, 95\% Cl: [-0.16,-0.11], $P=1.1 \times 10^{-24}$ ), and blood glucose (beta $=-0.13,95 \% \mathrm{Cl}:[-0.15,-0.10]$, $\left.P=5.5 \times 10^{-18}\right)$. Collectively, our results implicate loss of MAP3K15 as a protective factor for diabetes.

Most of the protective MAP3K15 signals emerged for T2DM phenotypes (Supplementary Table 1A). To determine if MAP3K15 loss also protects from T1DM, we defined a T1DM-specific phenotype in the UK Biobank ( $N=881$ cases) using available diagnostic information (Methods). The effect of MAP3K15 recessive variants on T1DM remained in the protective direction, but the association did not achieve study-wide significance at the current T1DM sample size (OR $=0.52,95 \% \mathrm{Cl}:[0.25,1.09], P=0.09)$.

\section{Complete versus partial loss of MAP3K15}

Given that the MAP $3 K 15$ associations emerged strongest among the recessive model, we next tested whether the effect of MAP $3 K 15$ loss on diabetes could be dose dependent. Since MAP3K15 resides on chromosome $\mathrm{X}$, hemizygous male PTV carriers are expected to have complete loss of the protein, and heterozygous female carriers are expected to have a $50 \%$ loss. Consistent with a dose-dependent effect, we found that hemizygous male carriers of European ancestry $(\mathrm{N}=1,216)$ demonstrated a $40 \%$ decreased risk of developing diabetes compared to male non-carriers $\left(\mathrm{OR}=0.60,95 \% \mathrm{Cl}:[0.45,0.81], P=7.2 \times 10^{-4}\right)$ (Supplementary Table 5). In comparison, heterozygous female carriers $(N=2,604)$ had a $23 \%$ reduced risk of diabetes compared to female non-carriers $(\mathrm{OR}=0.77 ; 95 \% \mathrm{Cl}$ : $[0.61$, 0.99], $P=0.04$ ) (Figure 1C). Decrease in $\mathrm{HbA} 1 \mathrm{c}$ levels were also three times greater in hemizygous male carriers (beta $=-0.21,95 \% \mathrm{Cl}$ : $\left.[-0.26,-0.15], P=1.2 \times 10^{-11}\right)$ (Supplementary Table 5) than in heterozygous female carriers (beta $=-0.07,95 \% \mathrm{Cl}:[-0.11,-0.04], P=5.3 \times 10^{-}$ $\left.{ }^{5}\right)$ (Figure 1D). The significantly stronger effects observed with complete loss of MAP3K15 as compared to partial (50\%) loss (Figures 1C and 1D) suggests an additive protective effect of $M A P 3 K 15$ loss on diabetes-related traits. 
medRxiv preprint doi: https://doi.org/10.1101/2021.11.14.21266328; this version posted November 15,2021 . The copyright holder for this preprint (which was not certified by peer review) is the author/funder, who has granted medRxiv a license to display the preprint in

It is made available under a CC-BY-NC-ND 4.0 International license

A

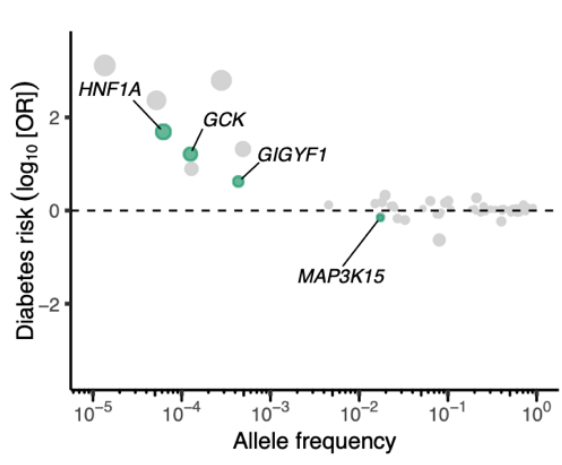

Collapsing ExWAS

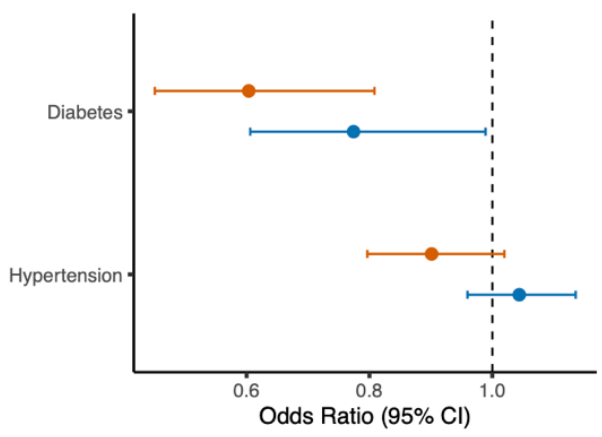

B

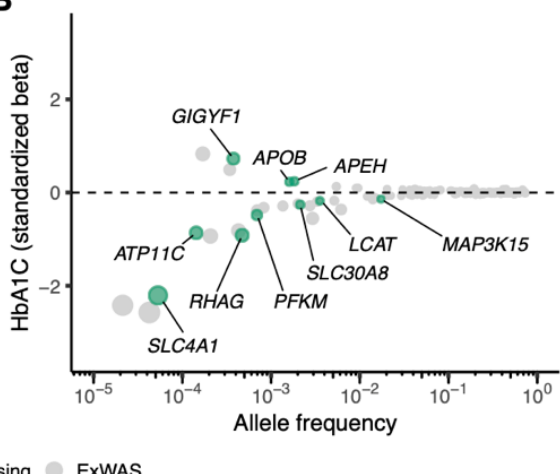

D

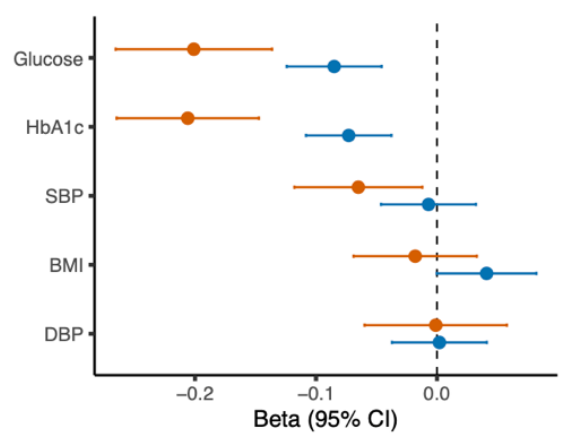

- Heterozygous F (50\% loss) - Hemizygous M (100\% loss)



Figure 1. Genetic associations with diabetes and related traits among the European ancestry participants in the UK Biobank. (A) Odds ratios and allele frequencies of gene-level (collapsing) and variant-level (ExWAS) associations $\left(p<1 \times 10^{-8}\right)$ with diabetes diagnoses. (B) Effect sizes and allele frequencies of gene-level (collapsing) and variant-level (ExWAS) associations $\left(p<1 \times 10^{-8}\right)$ with haemoglobin $A 1 c(H b A 1 c)$. Allele frequencies on the $x$-axis are plotted on a log10 scale in both (A) and (B). (C) Odds ratios of partial loss (i.e., heterozygous female PTV carriers) and complete loss (i.e., hemizygous male PTV carriers) of MAP3K15 for diabetes and hypertension diagnoses. (D) Effect sizes of partial loss (i.e., heterozygous female PTV carriers) and complete loss (i.e., hemizygous male PTV carriers) of $M A P 3 K 15$ for various cardiovascular and metabolic traits related to diabetes. $(\mathrm{DBP}=$ Diastolic Blood Pressure, $\mathrm{SBP}=$ Systolic Blood Pressure, $\mathrm{BMI}=$ Body Mass Index) (E) Lollipop plot depicting MAP3K15 PTVs (stop gain and frameshift variants) observed among hemizygous males of European ancestry. Essential splice variants were not included. The two most frequent PTVs have been annotated with allele frequencies from participants of European ancestry. There were no carriers in common to the two PTVs among the European ancestry males. The y-axis is capped at 40 .

We also found that the contributing PTVs occurred throughout the MAP3K15 gene 
medRxiv preprint doi: https://doi.org/10.1101/2021.11.14.21266328; this version posted November 15,2021 . The copyright holder for this preprint (which was not certified by peer review) is the author/funder, who has granted medRxiv a license to display the preprint in It is made available under a CC-BY-NC-ND 4.0 International license.

146 frequent and accounted for $74 \%$ of the European-ancestry hemizygous male carriers: 147 Arg1122* $(\mathrm{MAF}=0.11 \%)$ and Arg1136* $(\mathrm{MAF}=0.35 \%)$ (Figure 1E; Supplementary Table

148 6). Although proximally close, none of the European-ancestry males carried both PTVs. 149 Consistent with this, the two PTVs were found to be independently associated with reduced 150 risk of diabetes (Arg1122*: OR $=0.33,95 \% \mathrm{Cl}:[0.13,0.80], P=0.02 ; \operatorname{Arg} 1136^{*}: \mathrm{OR}=0.60$, $15195 \% \mathrm{Cl}:[0.41,0.88], P=0.01)$ and lower HbA1c levels (Arg1122*: beta $=-0.30,95 \% \mathrm{Cl}:[-$ $1520.44,-0.15], P=4.3 \times 10^{-5} ;$ Arg1136*: beta $=-0.20,95 \% \mathrm{Cl}:[-0.27,-0.12], P=1.3 \times 10^{-6}$ ) 153 (Supplementary Table 7). When excluding these two PTVs from the collapsing test, carriers 154 of the remaining 38 ultra-rare MAP3K15 PTVs observed among the European-ancestry males 155 also had significantly reduced $\mathrm{HbA} 1 \mathrm{c}$ levels (beta $=-0.16,95 \% \mathrm{Cl}$ : $[-0.28,-0.05], P=5.2 \times 10^{-}$

$156{ }^{3}$ ). Due to reduced sample and, thus, statistical power, the association with reduced diabetes 157 risk $(\mathrm{OR}=0.84,95 \% \mathrm{Cl}:[0.50,1.39], P=0.49)$ did not achieve significance among the 158 remaining ultra-rare PTV carriers (Supplementary Table 7).

159

\section{Replication analysis}

161 Using summary statistics from the FinnGen study release 5 [ $N=218,792]$, we next aimed to replicate the MAP3K15 findings. The two more frequent MAP3K15 PTVs (Arg1122* and Arg1136*) were both well-imputed (INFO scores: 0.98 and 0.84 , respectively) in the FinnGen dataset. The Arg1122* PTV (rs140104197), which is three times more common in individuals of Finnish descent $(\mathrm{MAF}=0.33 \%)$ than in UKB Europeans $(\mathrm{MAF}=0.11 \%)$, was significantly associated with protection from both T1DM $\left(\mathrm{OR}=0.58, P=4.9 \times 10^{-4}\right)$ and T2DM $(\mathrm{OR}=0.82$, $P=0.04$ ) (Supplementary Table 8). Arg1136* (rs148312150) was less frequent in individuals of Finnish descent compared to Europeans in UKB (MAF: $0.16 \%$ versus $0.35 \%$ ), and it individually did not reach statistical significance with any diabetes-related phenotype in FinnGen. There were no other MAP3K15 PTVs detected in FinnGen.

MAP3K15 protective PTV signal is not associated with changes in body mass index or metabolic derangements

174 Obesity, which can lead to increased insulin resistance, is a strong risk factor for T2DM. To 175 investigate whether the effect of MAP3K15 on diabetes is mediated via adiposity, we further 176 tested the effect of complete loss of MAP3K15 adjusting for BMI. The associations between 177 hemizygous MAP3K15 PTV carrier status and both HbA1c (BMI-unadjusted: beta $=-0.21$, $17895 \% \mathrm{Cl}$ : [-0.15,-0.26], $P=1.2 \times 10^{-11}$; BMI-adjusted: beta $=-0.20,95 \% \mathrm{Cl}:[-0.14,-0.26], P=$ $1791.1 \times 10^{-11}$ ) and diabetes (BMI-unadjusted: $\mathrm{OR}=0.60,95 \% \mathrm{Cl}:[0.45,0.81], P=7.2 \times 10^{-4}$; BMI180 adjusted: $\mathrm{OR}=0.59,95 \% \mathrm{Cl}:[0.43,0.79], P=5.3 \times 10^{-4}$ ) remained consistent after adjusting 181 for BMI, suggesting the protective effect of MAP3K15 loss on diabetes is unlikely to be 182 mediated via insulin resistance and is likely to benefit individuals irrespective of BMI. 
medRxiv preprint doi: https://doi.org/10.1101/2021.11.14.21266328; this version posted November 15, 2021. The copyright holder for this preprint (which was not certified by peer review) is the author/funder, who has granted medRxiv a license to display the preprint in It is made available under a CC-BY-NC-ND 4.0 International license .

Certain genes that influence diabetes risk can also impact other clinically relevant biomarkers. For example, although PTVs in GIGYF1 are associated with increased risk of diabetes, they are also associated with reduced low-density lipoprotein cholesterol ${ }^{12}$. We thus tested whether collapsing analyses of MAP3K15 rare non-synonymous variants associated with any of 168 NMR-based blood metabolite measurements available for approximately 120,000 of the UKB participants. Among the studied metabolites, MAP3K15 was only associated with reduced glucose ("ptv5pcnt" model, beta $=-0.16,95 \% \mathrm{Cl}:[-0.23,-0.10], P=$ $\left.4.4 \times 10^{-7}\right)$.

\section{Potential MAP3K15 inhibition safety liabilities}

192 We observed that approximately 1 in every $150(0.6 \%)$ European-ancestry male participants 193 in the UKB has a lifetime systemic absence of functional MAP3K15. Given these individuals are participants in a generally healthy cohort such as the UKB provides considerable support to the tolerability of MAP3K15 inhibition in humans. This is further supported by this gene's $\mathrm{pLI}$ score of 0.0 , which is a measure of the tolerance of a given gene to protein-truncating variants ${ }^{13}$.

However, we sought to systematically evaluate whether therapeutically inhibiting MAP3K15 could associate with on-target adverse phenotypes. To achieve this, we surveyed associations between non-synonymous variants in MAP3K15 and 15,719 clinical phenotypes in the UKB, as described previously ${ }^{10}$. We did not observe any significant adverse phenotypic associations $\left(P<1 \times 10^{-8}\right)$ in individuals with MAP3K15 loss ("ptv", "ptv5pcnt", and "rec" collapsing models) in either the individual ancestry or the pan-ancestry analysis. We next tested whether there were any other non-diabetes MAP3K15 associations at a less conservative $\mathrm{p}$-value threshold $\left(P<1 \times 10^{-4}\right)$. In the European ancestry participants, there were no associations in the "ptv" or "ptv5pcnt" model even at this more liberal p-value cut-off. There were two associations observed in models that included missense variants: hepatomegaly with splenomegaly and diseases of the tongue (Supplementary Table 9A).

Finally, as previous animal model studies have highlighted that knockout of Map3k15

210 in mice models introduces a hypertensive phenotype ${ }^{14}$, we sought to look at this specific 211 phenotype in greater detail. Among the large European sample, there was no evidence of 212 increased risk to hypertension. Instead, the effect of MAP3K15 PTVs on human blood 213 pressure-related traits seems to be in the protective direction. The hemizygous MAP3K15 PTV 214 carriers (i.e., complete loss of MAP3K15) showed a modest effect in the protective direction 215 for both hypertension ('Union\#l10\#/10 Essential (primary) hypertension': OR = 0.90, 95\% Cl: $216[0.80,1.02], P=0.10$ ) and systolic blood pressure (beta $=-0.07,95 \% \mathrm{Cl}:[-0.12,-0.01], P=$ 217 0.01) (Figures 1C and 1D; Supplementary Table 10). Similarly, among the independent 218 FinnGen cohort, the Finnish-enriched MAP3K15 PTV (Arg1122* (rs140104197)) that 
medRxiv preprint doi: https://doi.org/10.1101/2021.11.14.21266328; this version posted November 15, 2021. The copyright holder for this preprint (which was not certified by peer review) is the author/funder, who has granted medRxiv a license to display the preprint in It is made available under a CC-BY-NC-ND 4.0 International license .

219 associated strongly with T1DM and T2DM, replicated a modest protective effect on 220 hypertension $\left(\mathrm{OR}=0.84, P=8.5 \times 10^{-3}\right)$. Expanding our assessment to MAP3K15 missense 221 variants, the strongest signal for hypertension arises among participants of South Asian 222 ancestry $(\mathrm{N}=8,078)$, where the recessive collapsing model showed an association between

223 MAP3K15 and a hypertension phenotype ('41202\#Block/10-/15\#/10-/15 Hypertensive 224 diseases': $\mathrm{OR}=6.33,95 \% \mathrm{Cl}$ : [3.02,13.28], $P=4.8 \times 10^{-5}$ ) (Supplementary Table 9A). 225 Although not study-wide significant $\left(P<1 \times 10^{-8}\right)$, more importantly, this signal was driven by 226 MAP3K15 missense variants, with seven hemizygous missense carriers and one hemizygous 227 PTV carrier among affected males of South Asian descent (Supplementary Table 9B). A more detailed screen of MAP3K15 missense variants identified rs56381411 associating with an increased risk of hypertension in FinnGen (MAF $=1.5 \%, \mathrm{OR}=1.17, P=2.4 \times 10^{-7}$ ).

230 Evaluation of the effect of MAP3K15 missense variants in recessive form in European ancestry participants revealed a nominally significant association with a blood pressure phenotype in

232 the UK Biobank too ('Union\#R030\#R03.0 Elevated blood-pressure reading| without diagnosis of hypertension': OR $=1.44,95 \% \mathrm{Cl}$ : [1.02,2.03], $P=0.05)$.

Whereas certain missense variants in MAP3K15 may increase the risk of hypertension, there is no evidence for PTVs in this gene conferring risk. Collectively, these findings suggest a potential MAP3K15 allelic series, whereby putative gain-of-function missense variants in might increase the risk of hypertension while PTV (putative loss-of-function) alleles protect against hypertension. Further functional characterisation of variation in MAP3K15 is required to better understand their variable effects on blood pressure- and diabetes-related traits. Altogether, the lack of association between PTVs in MAP3K15 and any adverse phenotypes suggest that there is a low human safety risk for selective therapeutic inhibition of MAP3K 15.

\section{Orthogonal evidence}

244 Because MAP3K15 appears to be associated with reduced risk of T1DM and T2DM and is not associated with $\mathrm{BMI}$, the data suggests that the protective effect is unlikely to be operating through insulin sensitisation. Physiologically, MAP3K15 encodes a mitogen-activated protein kinase that is known to play a role in regulating cell stress and apoptotic cell-death ${ }^{15}$. To gain more insight into potential protective mechanisms, we examined the tissue expression profiles of MAP3K15 in GTEx ${ }^{16}$. MAP3K15 is most strongly expressed in the adrenal glands and is also expressed at relatively lower levels in the spleen, kidney, pancreas, and pituitary glands (Figure 2A). Single-cell expression data from human pancreatic endocrine cells indicate that MAP3K15 is most strongly expressed in islet cell subpopulations, including $\alpha-, \beta-$ and $\delta-$ cells ${ }^{17-21}$ (Figure 2B). Its ubiquitous expression profile in the adrenals could suggest a role in mediating catecholamine biosynthesis or glucocorticoid response ${ }^{22}$. Alternatively, its effect could be mediated through maintenance of endogenous pancreatic islet cells. 
medRxiv preprint doi: https://doi.org/10.1101/2021.11.14.21266328; this version posted November 15,2021 . The copyright holder for this preprint (which was not certified by peer review) is the author/funder, who has granted medRxiv a license to display the preprint in

It is made available under a CC-BY-NC-ND 4.0 International license .

To further explore whether MAP3K15 contributes to the pathophysiology of diabetes in pancreatic cells, we assessed differential gene expression data from a prior study focused on Maturity Onset Diabetes of the Young (MODY) ${ }^{23}$, an early-onset, autosomal dominant form of noninsulin-dependent diabetes. In this study, expression profiling was performed on a mouse insulinoma cell line carrying mutations in the MODY-associated gene Nkx6-1. In all three mutations tested, including a positive control mutant known to impair Nkx6-1 as well as two MODY-associated genetic variants, MAP3K15 was found to be the most significantly upregulated gene (Figure 2C). This finding suggests that increased MAP3K15 activity may mediate the pathophysiology of diabetes, potentially through an increased rate of beta cell loss.

A

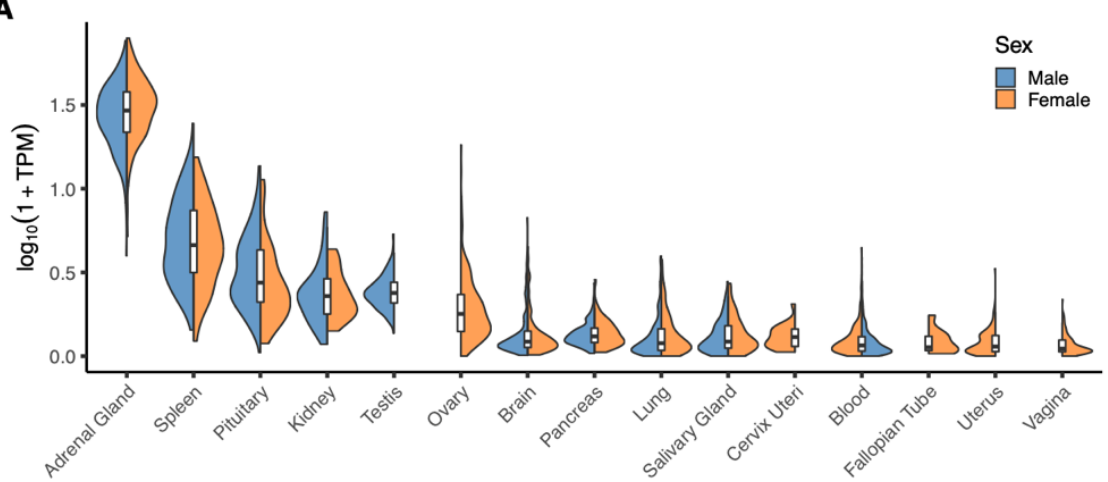

B

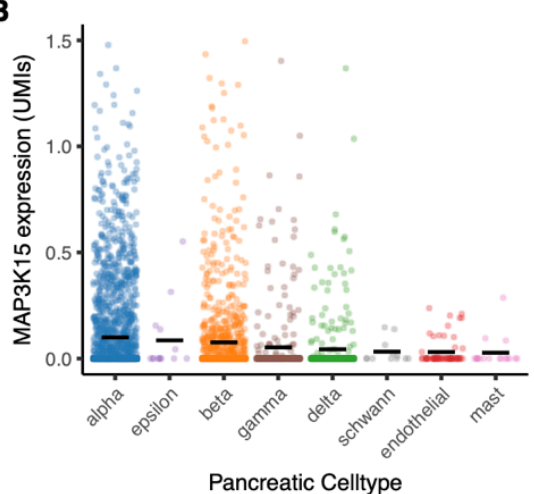

C

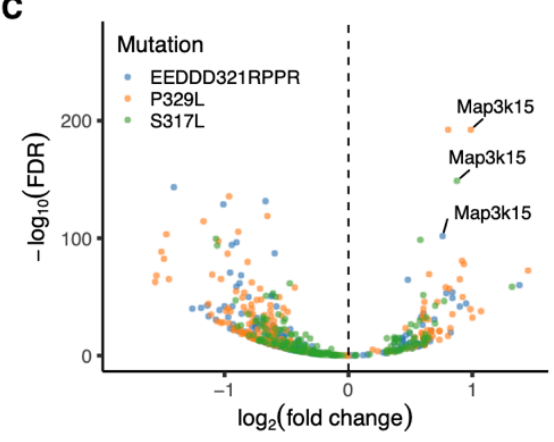

Figure 2. Tissue expression profile of MAP3K15. (A) Expression of $M A P 3 K 15$ in human tissues contained in the GTEx database. TPM = transcripts per million. We only included tissues with a median TPM $>0.1$. (B) MAP3K15 expression in major subpopulations of human pancreatic cells derived from a previously published single-cell RNA-sequencing dataset $^{17-21}$. (C) Volcano plot depicting differential gene expression in mouse insulinoma cell lines stably expressing three variants in Nkx6-1: two MODY-associated variants (P329L and S317L) and a control mutation known to functionally impair Nkx6-1 $\left(\right.$ EEDD321RPPR) ${ }^{23}$.

Orthogonal evidence derived from two in silico tools, Gene-SCOUT ${ }^{24}$ and phenome-wide Mantis-ML ${ }^{25}$ provide further support for a role of MAP $3 K 15$ in diabetes. Gene-SCOUT provides biomarker fingerprint similarity between any pair of human genes based on UKB exome 
medRxiv preprint doi: https://doi.org/10.1101/2021.11.14.21266328; this version posted November 15,2021 . The copyright holder for this preprint (which was not certified by peer review) is the author/funder, who has granted medRxiv a license to display the preprint in

It is made available under a CC-BY-NC-ND 4.0 International license .

sequencing cohort statistics using 1,419 quantitative traits ${ }^{24}$. Entering MAP3K15 as the seed gene in this tool highlights $S \angle C 30 A 8$ as having the most similar human biomarker profile to what is observed for MAP3K15 (Figures 3A and 3B; Supplementary Figure 2). SLC30A8, a zinc transporter gene (ZnT8) expressed in pancreatic islet $\alpha$ - and $\beta$-cells, is reported to have a protective effect against T2DM potentially via increased glucose responsiveness ${ }^{26,27}$. Mantis-ML, an automated machine-learning framework designed to identify gene-phenotype relationships based on compendium of publicly available disease-specific features (such as tissue expression, preclinical models, genic intolerance, among others), suggests disorders related to impaired glucose homeostasis, including "diazoxide-resistant diffuse hyperinsulinism" and "hyperinsulinemic hypoglycaemia" (Figure $3 \mathrm{C}$ ), among the top $1 \%$ of human phenotypes that MAP3K15 may have a role in (Supplementary Table 11). While mantis-ml does not indicate whether a gene may have a causal versus protective role for a given phenotype, these results converge on MAP3K15's involvement in diabetes-related biology. Both these tools provide diverse and independent support of a biological role for MAP3K15 in human diabetes.

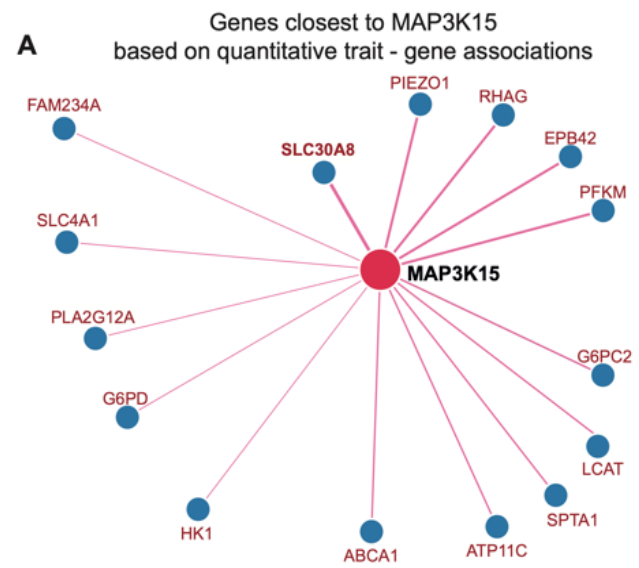

B

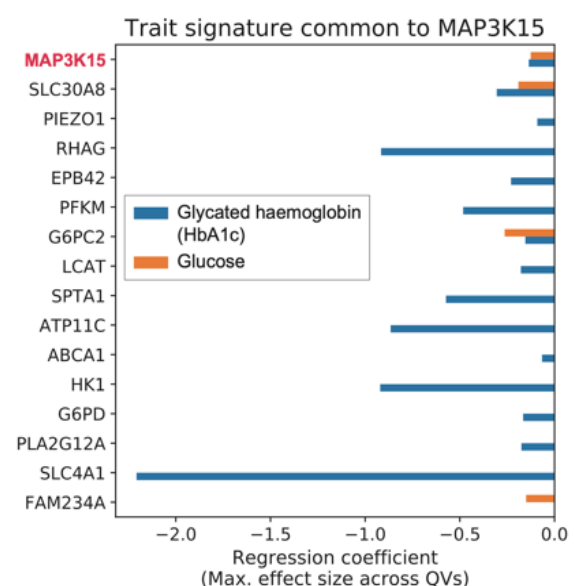

C

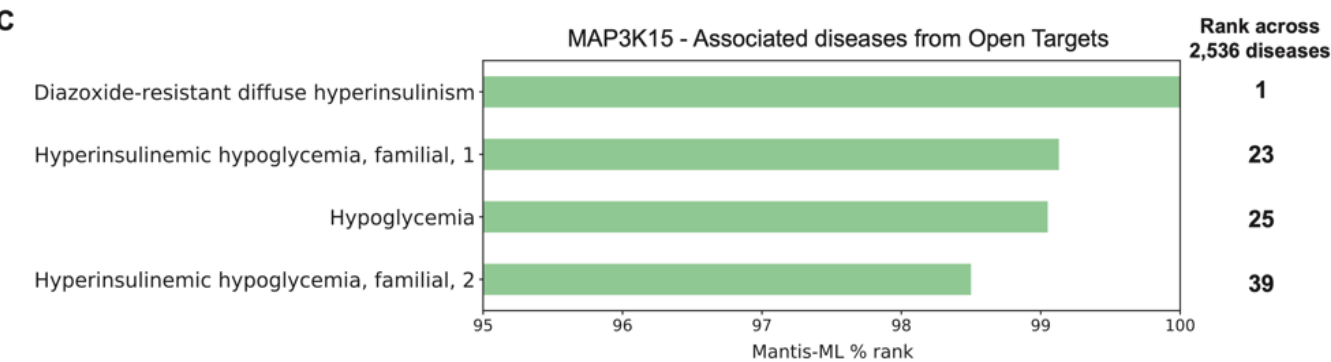

Figure 3. MAP3K15 quantitative trait and disease signatures. (A) Genes with most similar quantitative trait profiles as MAP $3 K 15$ in the UK Biobank, derived from Gene-SCOUT ${ }^{24}$. (B) Linear regression coefficients for $\mathrm{HbA1c}$ and glucose from collapsing analysis models for genes in panel A (genes are sorted from top to bottom in decreasing order of similarity to MAP3K15). QVs = qualifying variants. (C) Mantis $\mathrm{ML}^{25}$ predictions of MAP3K15 disease associations. 
medRxiv preprint doi: https://doi.org/10.1101/2021.11.14.21266328; this version posted November 15, 2021. The copyright holder for this preprint (which was not certified by peer review) is the author/funder, who has granted medRxiv a license to display the preprint in

It is made available under a CC-BY-NC-ND 4.0 International license .

\section{Discussion}

303 This exome-sequencing study of 456,796 UKB participants increases our understanding of 304 high-effect size genetic factors involved in both propensity for and protection from diabetes in 305 humans. We found that recessive loss of MAP3K15 reduces the risk of developing diabetes 306 by approximately $40 \%$. This was supported by the association between recessive loss of 307 MAP3K15 and decreased $\mathrm{HbA} 1 \mathrm{c}$ and blood glucose. Although the protective signal was 308 strongest for T2DM, the effect of MAP3K15PTVs was also in the protective direction for T1DM 309 risk in both the UKB and FinnGen. This supports the notion that despite being defined as 310 distinct clinical entities, T1DM and T2DM share some common pathophysiological pathways 311 such as $\beta$-cell dysfunction ${ }^{28,29}$.

312 Crucially, loss-of-function mutations that protect against human disease can act as 313 direct in vivo validation of therapeutic targets; thus, MAP $3 K 15$ inhibition could have therapeutic 314 value in both T1DM and T2DM. Given the relatively modest decrease in glucose $(0.25 \mathrm{mmol} / \mathrm{L})$ 315 and $\mathrm{HbA} 1 \mathrm{c}$ levels $(1.36 \mathrm{mmol} / \mathrm{mol})$ that associate with MAP3K15 loss, one possibility is that 316 the observed protective effect on clinical diabetes is not primarily mediated through glucose / $317 \mathrm{HbA} 1 \mathrm{c}$ reduction. We also found that the protective effect of MAP3K15 loss is independent of 318 BMI, which might suggest that its effect on diabetes is unrelated to insulin sensitivity, though 319 we note that the relationship between BMI and insulin resistance is correlational. While not 320 currently available for UK Biobank participants, quantitative measures of insulin resistance in 321 MAP3K15 PTV carriers in future studies could illuminate whether the protective mechanism is 322 indeed unrelated to the insulin resistance pathway. Nonetheless, our results suggest that 323 therapeutic selective inhibition of MAP3K15 could also benefit patients living with diabetes who are in the low-to-normal BMI range.

Through a phenome-wide association study in the 454,796 human participants, we showed that MAP3K15 loss is not significantly associated with any phenotypes that would suggest safety concerns due to therapeutic inhibition of this target. Prior work observed that knocking out Map3k15 in mice led to hypertension ${ }^{14}$. Interestingly, we found that in humans, PTVs appeared to provide a protective effect on hypertension, whereas certain missense variants in MAP3K15 appeared to increase the risk of hypertension. Collectively, these results not only highlight possible species-specific differences upon loss of MAP3K15, but also suggest an allelic series in humans, in which missense variants exert a spectrum of loss- to gain-of-function effects. Future functional characterisation of clinically associated missense variants and PTVs could provide further insights into this potential allelic series.

In our previously published work, MAP3K 15 was one of 15 genes that had unequivocal 
medRxiv preprint doi: https://doi.org/10.1101/2021.11.14.21266328; this version posted November 15, 2021. The copyright holder for this preprint (which was not certified by peer review) is the author/funder, who has granted medRxiv a license to display the preprint in It is made available under a CC-BY-NC-ND 4.0 International license.

337 is that, with the addition of 150,000 more exomes, we also observe a statistically significant 338 reduced risk for diabetes diagnosis, in addition to the biomarker associations. This finding has 339 important implications for the interpretation of genetic biomarker associations. Crucially, not 340 all genetic associations with clinically relevant biomarkers will be related to the 341 pathophysiology of the underlying disease. Here, anchoring biomarker genetic signals with 342 relevant clinical endpoints can help identify those that are more likely to modify the underlying 343 disease. Therapeutically, this suggests that inhibiting MAP3K15 may target the core 344 pathophysiology of the disease process rather than targeting reduced blood glucose.

345 The tissue expression profile of MAP3K15 demonstrates predominant expression in 346 adrenal glands and several islet cell subpopulations, suggesting that MAP $3 K 15$ might be 347 involved in pancreatic islet cell functional maintenance and / or stress response pathways. 348 Dysregulation of stress response in diabetes ${ }^{30,31}$ and the role of ASK (MAP kinase) family of 349 genes in regulating stress response (e.g., apoptosis, inflammation) to external stimuli ${ }^{14,15}$ offer 350 further support to these mechanisms. These provide important clues regarding the otherwise 351 unknown pathways that mediate the protective effect of MAP3K15 natural inhibition on 352 diabetes. 
medRxiv preprint doi: https://doi.org/10.1101/2021.11.14.21266328; this version posted November 15, 2021. The copyright holder for this preprint (which was not certified by peer review) is the author/funder, who has granted medRxiv a license to display the preprint in

It is made available under a CC-BY-NC-ND 4.0 International license .

\section{Methods}

\section{Cohorts}

359 Discovery genetic association studies were performed using the 454,796 exomes available in 360 the UK Biobank (UKB) cohort $^{32}$. The UKB is a prospective study of approximately 500,000 361 participants aged 40-69 years at time of recruitment. Participants were recruited in the UK 362 between 2006 and 2010 and are continuously followed. The average age at recruitment for 363 sequenced individuals was 56.5 years and $54 \%$ of the sequenced cohort is of female genetic 364 sex. Participant data include health records that are periodically updated by the UKB, self365 reported survey information, linkage to death and cancer registries, collection of urine and 366 blood biomarkers, imaging data, accelerometer data and various other phenotypic end points. 367 All study participants provided informed consent and the UK Biobank has approval from the North-West Multi-centre Research Ethics Committee (MREC; 11/NW/0382).

Replication of the findings in the UKB was performed using the summary statistics from the FinnGen study. The FinnGen cohort (release 5) includes 218,792 individuals from Finland with genotype and health registry data. Phenotypes have been derived from nationwide health registries. Patients and control subjects in FinnGen provided informed consent for biobank research, based on the Finnish Biobank Act. Alternatively, older research cohorts, collected prior the start of FinnGen (in August 2017), were collected based on study-specific consents and later transferred to the Finnish biobanks after approval by Fimea, the National Supervisory Authority for Welfare and Health. Recruitment protocols followed the biobank protocols approved by Fimea. The Coordinating Ethics Committee of the Hospital District of Helsinki and Uusimaa (HUS) approved the FinnGen study protocol Nr HUS/990/2017. The FinnGen study is approved by Finnish Institute for Health and Welfare.

\section{Phenotypes}

382 We harmonized the UKB phenotype data as previously described ${ }^{10}$. Briefly, we used PEACOK 383 and union mapping to parse binary and quantitative traits included in the February 2020 UKB release (accessed March 27, 2020; UKB application 26041). Here, we considered 90 binary (clinical) phenotypes related to diabetes available in the UKB (Supplementary Tables 1A),

386 three quantitative traits related to diabetes (blood glucose, glycosylated haemoglobin and body mass index), and two quantitative traits related to hypertension (systolic blood pressure (SBP) and diastolic blood pressure (DBP)) (Supplementary Tables 1B).

389 Additionally, for a type 1 diabetes (T1DM)-specific analysis, we defined the case population

390 using ICD-9 and ICD-10 codes that captured T1DM diagnoses and the control population by excluding participants with any diabetes diagnoses. 
medRxiv preprint doi: https://doi.org/10.1101/2021.11.14.21266328; this version posted November 15, 2021. The copyright holder for this preprint (which was not certified by peer review) is the author/funder, who has granted medRxiv a license to display the preprint in It is made available under a CC-BY-NC-ND 4.0 International license .

392 For analyses involving SBP and DBP, we adjusted for commonly prescribed blood pressure medications (Supplementary Table 12).

\section{Genetic data}

396 Exome sequencing data for 454,988 UKB participants were generated at the Regeneron

397 Genetics Center (RGC) as part of a pre-competitive data generation collaboration between

398 AbbVie, Alnylam Pharmaceuticals, AstraZeneca, Biogen, Bristol-Myers Squibb, Pfizer,

399 Regeneron and Takeda with the UKB. Genomic DNA underwent paired-end 75-bp whole-

400 exome sequencing at Regeneron Pharmaceuticals using the IDT xGen v1 capture kit on the

401 NovaSeq6000 platform. Conversion of sequencing data in BCL format to FASTQ format and

402 the assignments of paired-end sequence reads to samples were based on 10-base barcodes,

403 using bcl2fastq v2.19.0. Initial quality control was performed by Regeneron and included sex

404 discordance, contamination, unresolved duplicate sequences and discordance with

405 microarray genotyping data checks.

406 In FinnGen, genotyping of the samples was done using a ThermoFisher Axiom custom array.

407 In addition to the core GWAS markers (about 500,000), it contains 116,402 coding variants 408 enriched in Finland, 10,800 specific markers for the HLA/KIR region, 14,900 ClinVar variants, 4,600 pharmacogenomic variants and 57,000 selected markers.

410

411 AstraZeneca Centre for Genomics Research (CGR) bioinformatics pipeline

412 The 454,796 UKB exome sequences were re-processed at AstraZeneca from their unaligned

413 FASTQ state. A custom-built Amazon Web Services (AWS) cloud compute platform running

414 Illumina DRAGEN Bio-IT Platform Germline Pipeline v3.0.7 was used to align the reads to the

415 GRCh38 genome reference and perform single-nucleotide variant (SNV) and insertion and 416 deletion (indel) calling. SNVs and indels were annotated using SnpEFF v4.3 ${ }^{33}$ against

417 Ensembl Build 38.92. We further annotated all variants with their genome Aggregation 418 Database (gnomAD) MAFs (gnomAD v2.1.1 mapped to GRCh38) ${ }^{13}$. We also annotated 419 variants using MTR score ${ }^{34}$ to identify if they mapped to genic regions under constraint for 420 missense variants and REVEL scores ${ }^{35}$ for their predicted deleteriousness.

\section{Additional quality control}

423 To complement the quality control performed by Regeneron Genomics Centre, we passed the

424 UKB exome sequences through our internal bioinformatics pipeline as previously described ${ }^{10}$.

425 Briefly, for UKB, we excluded from our analyses an additional 122 sequences that achieved a 426 VerifyBAMID freemix (measure of DNA contamination) of more than 4\%, and an additional 5 427 sequences where less than $94.5 \%$ of the consensus coding sequence (CCDS release 22) 428 achieved a minimum of ten-fold read depth. The cohort was also screened to remove participants that were second-degree relatives or closer (equivalent to kinship coefficient > 
medRxiv preprint doi: https://doi.org/10.1101/2021.11.14.21266328; this version posted November 15, 2021. The copyright holder for this preprint (which was not certified by peer review) is the author/funder, who has granted medRxiv a license to display the preprint in It is made available under a CC-BY-NC-ND 4.0 International license .

430

431

432

433

434

435

436

437

438

439

440

441

442

443

444

445

446

447

448

449

450

451

452

453

454

455

456

457

458

459

460

461

462

463

464

465

466

0.0884), as determined using the --kinship function in KING v2.2.3 ${ }^{36}$. After the above quality control steps, there remained 412,394 unrelated UKB sequences of any genetic ancestry that were available for analyses presented in this study.

\section{Genetic ancestry}

The primary discovery analysis was performed in UKB participants of European ancestry. We used the available exome sequencing data to perform genetic ancestry prediction in PEDDY v0.4.2. We leveraged sequences from the 1,000 Genomes Project as population references ${ }^{37}$ for ancestry estimation. 394,695 (93\%) of the 422,488 unrelated UKB participants - that had European ancestry prediction $>0.99$ and were within 4 SD of the means for the top four principal components - were selected for the European-ancestry case-control analyses. We also used the PEDDY-derived ancestry predictions to identify non-European ancestry populations that had at least 1,000 individuals with exome sequences to perform pan-ancestry collapsing analyses (see the section 'Collapsing analyses'). This identified 7,412 African, 2,209 East Asian and 8,078 South Asian UKB participants based on predicted ancestry $>0.95$ for the respective ancestries.

\section{Discovery analyses}

\section{Collapsing analyses}

We performed our previously described gene-level collapsing analysis framework ${ }^{10}$ for 90 binary and 5 quantitative traits related to diabetes. We included 10 non-synonymous collapsing models, including 9 dominant and one recessive model, plus an additional synonymous variant model as an empirical negative control (Supplementary Table 2). For the dominant collapsing models, the carriers of at least one qualifying variant $(\mathrm{QV})$ in a gene were compared to the non-carriers. In the recessive model, individuals with two copies of QVs either in homozygous or putatively compound heterozygous form were compared to the noncarriers. Hemizygous genotypes for $X$ chromosome genes also qualified for the recessive model.

Using SnpEff annotations, we defined synonymous variants as those annotated as 'synonymous_variant'. We defined PTVs as variants annotated as exon_loss_variant, frameshift_variant, start_lost, stop_gained, stop_lost, splice_acceptor_variant, splice_donor_variant, gene_fusion, bidirectional_gene_fusion, rare_amino_acid_variant, and transcript_ablation. We defined missense as: missense_variant_splice_region_variant, and missense_variant. Nonsynonymous variants included: exon_loss_variant, frameshift_variant, start_lost, stop_gained, stop_lost, splice_acceptor_variant, splice_donor_variant, gene_fusion, bidirectional_gene_fusion, rare_amino_acid_variant, transcript_ablation, conservative_inframe_deletion, conservative_inframe_insertion, 
medRxiv preprint doi: https://doi.org/10.1101/2021.11.14.21266328; this version posted November 15, 2021. The copyright holder for this preprint (which was not certified by peer review) is the author/funder, who has granted medRxiv a license to display the preprint in It is made available under a CC-BY-NC-ND 4.0 International license .

482

disruptive_inframe_insertion,

disruptive_inframe_deletion, missense_variant_splice_region_variant, missense_variant, and protein_altering_variant.

For binary traits, the difference in the proportion of cases and controls carrying QVs in a gene was tested using a Fisher's exact two-sided test. For quantitative traits, the difference in mean between the carriers and non-carriers of QVs was determined by fitting a linear regression model, correcting for age, sex and medication intake (for SBP and DBP).

For all models, we applied the following quality control filters: minimum coverage 10X; annotation in CCDS transcripts (release 22; approximately $34 \mathrm{Mb}$ ); at most $80 \%$ alternate reads in homozygous genotypes; percent of alternate reads in heterozygous variants $\geq 0.25$ and $\leq 0.8$; binomial test of alternate allele proportion departure from $50 \%$ in heterozygous state $\mathrm{P}>1 \times 10^{-6} ; \mathrm{GQ} \geq 20$; FS $\leq 200$ (indels) $\leq 60$ (SNVs); $\mathrm{MQ} \geq 40 ; \mathrm{QUAL} \geq 30$; read position rank sum score $\geq-2 ; M Q R S \geq-8$; DRAGEN variant status = PASS; the variant site achieved ten-fold coverage in $\geq 25 \%$ of gnomAD exomes, and if the variant was observed in gnomAD exomes, the variant achieved exome $z$-score $\geq-2.0$ and exome $M Q \geq 30$. We excluded 46 genes that we previously found associated with batch effects ${ }^{10}$.

\section{Pan-ancestry collapsing analyses}

We performed additional collapsing analysis in each individual non-European ancestral population as described above. For binary traits, we then performed a pan-ancestry analysis using our previously introduced approach ${ }^{10}$ of applying a Cochran-Mantel-Haenszel test to generate combined $2 \times 2 \times N$ stratified P-values, with $\mathrm{N}$ representing up to all four genetic ancestry groups. For quantitative traits, the pan-ancestry analysis was performed using a linear regression model that included the following covariates: age, sex, categorical ancestry (European, African, East Asian or South Asian), and top five ancestry principal components.

\section{Variant-level (ExWAS) analyses}

We performed variant-level association tests in addition to the gene-level collapsing analyses for the 90 binary and 5 quantitative traits related to diabetes. We tested 3.3 million variants identified in at least six individuals from the 394,695 predominantly unrelated European ancestry UKB exomes as previously described ${ }^{10}$. In summary, variants were required to pass the following quality control criteria: minimum coverage 10X; percent of alternate reads in heterozygous variants $\geq 0.2$; binomial test of alternate allele proportion departure from $50 \%$ in heterozygous state $P>1 \times 10^{-6}$; genotype quality score $(G Q) \geq 20$; Fisher's strand bias score $(F S) \leq 200$ (indels) $\leq 60$ (SNVs); mapping quality score $(M Q) \geq 40$; quality score $(Q U A L) \geq 30$; read position rank sum score (RPRS) $\geq-2$; mapping quality rank sum score $(M Q R S) \geq-8$; DRAGEN variant status = PASS; variant site is not missing (that is, less than 10X coverage) in $10 \%$ or more of sequences; the variant did not fail any of the aforementioned quality control 
medRxiv preprint doi: https://doi.org/10.1101/2021.11.14.21266328; this version posted November 15,2021 . The copyright holder for this preprint (which was not certified by peer review) is the author/funder, who has granted medRxiv a license to display the preprint in It is made available under a CC-BY-NC-ND 4.0 International license .

504

505

506

507

508

509

510

511

512

513

514

515

516

517

518

519

520

521

522

523

524

525

526

527

528

529

530

531

532

533

534

535

536

537

538

539

540

in $5 \%$ or more of sequences; the variant site achieved tenfold coverage in $30 \%$ or more of gnomAD exomes, and if the variant was observed in gnomAD exomes, $50 \%$ or more of the time those variant calls passed the gnomAD quality control filters (gnomAD exome AC/AC_raw $\geq 50 \%)$. $P$ values were generated adopting a Fisher's exact two-sided test. Three distinct genetic models were studied for binary traits: allelic ( $A$ versus $B$ allele), dominant $(A A$ $+A B$ versus $B B$ ) and recessive $(A A$ versus $A B+B B)$, where $A$ denotes the alternative allele and $B$ denotes the reference allele. For quantitative traits, we adopted a linear regression (correcting for age and sex) and replaced the allelic model with a genotypic ( $A A$ versus $A B$ versus $\mathrm{BB}$ ) test.

\section{Phenome-wide analysis for MAP3K15}

We performed a phenome-wide collapsing analysis for MAP3K15 with 15,719 binary phenotypes for each individual ancestry in the UKB. We harmonized and union mapped these phenotype data as previously described ${ }^{10}$. We included all 11 collapsing models in the PheWAS, as described above. The methodology used here was identical to our previously published PheWAS on 281,104 UKB participants ${ }^{10}$.

\section{P-value threshold}

We defined the study-wide significance threshold as $p<1 \times 10^{-8}$. We have previously shown using an n-of-1 permutation approach and the empirical null synonymous model that this threshold corresponds to a false positive rate of 9 and 2, respectively, out of $\sim 346.5$ million tests for binary traits in the setting of collapsing analysis PheWAS ${ }^{10}$.

\section{Replication analyses}

We performed replication analysis of the association between MAP3K15 and diabetes using the publicly available results from the GWAS in the FinnGen cohort. We accessed the association statistics for the phenome-wide analysis of non-synonymous variants within MAP3K15 through the FinnGen portal (release 5).

\section{Secondary association analyses}

A total of 40 unique PTVs in MAP3K15 were observed among the hemizygous male carriers. Two of these PTVs (Arg1122* and Arg1136*) were relatively more frequent. We excluded carriers of these two alleles and re-performed the collapsing analyses for the remaining MAP3K15 PTVs: Fisher's exact test for diabetes ('20002\#1220\#diabetes') and linear regression for $\mathrm{HbA} 1 \mathrm{c}$.

To determine whether the effect of complete loss of $M A P 3 K 15$ on diabetes is mediated via adiposity or the insulin resistance pathway, we performed additional analyses in which we 
medRxiv preprint doi: https://doi.org/10.1101/2021.11.14.21266328; this version posted November 15,2021 . The copyright holder for this preprint (which was not certified by peer review) is the author/funder, who has granted medRxiv a license to display the preprint in It is made available under a CC-BY-NC-ND 4.0 International license .

541 regressed $\mathrm{HbA1c}$ and the diabetes phenotype ('20002\#1220\#diabetes') on MAP3K15 PTV 542 carrier status in males, with BMI as the covariate.

543 To investigate the joint effects of complete loss of MAP3K15 and a nearby significantly 544 associated indel in PDHA1 (X-19360844-AAC-A), a gene that overlaps the 3'-UTR of 545 MAP3K15, we regressed $\mathrm{HbA1C}$ and the diabetes phenotype ('20002\#1220\#diabetes') on the 546 carrier status for the two frequent MAP3K15 PTVs (Arg1122* and Arg1136*) and the PDHA1 547 indel in males.

548

\section{Expression analyses}

550 We studied previously published bulk RNA-sequencing data available from a mouse 551 insulinoma cell line ( $\beta$-TC-6) transfected with three different clones carrying MODY-associated 552 variants in NKX6-125. We extracted the DESeq2-derived log fold changes, p-values, and FDR 553 values from the supplementary data. We determined tissue expression using the GTEx portal 554 (http://gtexportal.org/home/). For single-cell RNA-sequencing analysis, we examined eight 555 previously published datasets using tissue from human pancreatic islets spanning 27 healthy 556 donors, five technologies, and four laboratories ${ }^{17-21}$. Data was integrated using Seurat, as previously described ${ }^{38}$.

558

559

\section{Gene-SCOUT}

560 The tool Gene-SCOUT ${ }^{24}$ estimates similarity between genes by leveraging association 561 statistics from the collapsing analysis across 1,419 quantitative traits available in the UKB. We

562 utilised this tool to identify genes that were most similar to the 'seed gene' MAP3K15.

\section{Mantis-ML}

565 Mantis-ML ${ }^{25}$ is a gene prioritisation machine learning framework, integrating a diverse set of 566 annotations, including intolerance to variation, tissue expression and animal models. We used this tool to obtain the top disease predictions for MAP3K15 across 2,536 diseases parsed from

568 Open Targets. 
medRxiv preprint doi: https://doi.org/10.1101/2021.11.14.21266328; this version posted November 15,2021 . The copyright holder for this preprint (which was not certified by peer review) is the author/funder, who has granted medRxiv a license to display the preprint in

It is made available under a CC-BY-NC-ND 4.0 International license

Tables

\begin{tabular}{|c|c|c|c|c|c|c|c|}
\hline \multirow{2}{*}{$\begin{array}{l}\text { Gene } \\
\text { Name }\end{array}$} & \multirow{2}{*}{ Chr } & \multirow{2}{*}{$\begin{array}{l}\text { UKB diabetes-related clinical } \\
\text { phenotype }\end{array}$} & \multirow{2}{*}{$\begin{array}{c}\text { Most } \\
\text { significant } \\
\text { collapsing } \\
\text { model }\end{array}$} & \multicolumn{2}{|c|}{$\begin{array}{l}\text { Frequency of } \mathrm{QV} \\
\text { carriers }\end{array}$} & \multirow{2}{*}{$\begin{array}{c}\text { OR } \\
{[95 \% \mathrm{Cl}]}\end{array}$} & \multirow{2}{*}{$P$} \\
\hline & & & & Cases & Controls & & \\
\hline GCK & 7 & $\begin{array}{l}\text { 2443\#Diabetes diagnosed by } \\
\text { doctor }\end{array}$ & URmtr & $0.25 \%$ & $0.04 \%$ & $\begin{array}{c}6.75 \\
{[4.80,9.50]}\end{array}$ & $3.14 \times 10^{-21}$ \\
\hline GIGYF1 & 7 & $\begin{array}{l}\text { Union\#E11\#E11 Non-insulin- } \\
\text { dependent diabetes mellitus }\end{array}$ & ptv & $0.13 \%$ & $0.03 \%$ & $\begin{array}{c}4.00 \\
{[2.74,5.84]}\end{array}$ & $9.98 \times 10^{-11}$ \\
\hline HNF1A & 12 & $\begin{array}{c}\text { Source of report of E14 } \\
\text { (unspecified diabetes mellitus) }\end{array}$ & ptv5pcnt & $0.07 \%$ & $0.00 \%$ & $\begin{array}{c}39.18 \\
{[11.06,138.86]} \\
\end{array}$ & $1.39 \times 10^{-10}$ \\
\hline MAP3K15 & $x$ & $\begin{array}{l}\text { Union\#E14\#E14 Unspecified } \\
\text { diabetes mellitus }\end{array}$ & rec & $1.25 \%$ & $1.77 \%$ & $\begin{array}{c}0.70 \\
{[0.62,0.79]}\end{array}$ & $5.00 \times 10^{-9}$ \\
\hline
\end{tabular}

$570 \quad$ Table 1: Genes significantly associated with at least one diabetes-related clinical

571 phenotype in the gene-level collapsing analysis among European ancestry

572 participants in the UK Biobank

573 Genes across the exome were tested under 10 different non-synonymous collapsing models

574 with 90 diabetes-related clinical phenotypes available in the UK Biobank. The most

575 significant diabetes-related clinical phenotype and the corresponding association statistics

576 have been provided for the four genes that were significantly associated $\left(p<1 \times 10^{-8}\right)$ with at

577 least one diabetes-related clinical phenotype among European ancestry participants.

578 (Chr=Chromosome; QV=Qualifying Variant; OR=Odds Ratio, Cl=Confidence Intervals) 
medRxiv preprint doi: https://doi.org/10.1101/2021.11.14.21266328; this version posted November 15, 2021. The copyright holder for this preprint (which was not certified by peer review) is the author/funder, who has granted medRxiv a license to display the preprint in It is made available under a CC-BY-NC-ND 4.0 International license.

$580 \quad$ Competing Interests

581 A.N., R.S.D., A.R.H, D.V., A.A., B.B., K.M., B.Z., Q.W., K.S., D.S., B.C., D.S.P., MB., M.S., 582 D.B., R.F., M.N.P., and S.P are current employees and/or stockholders of AstraZeneca. 
medRxiv preprint doi: https://doi.org/10.1101/2021.11.14.21266328; this version posted November 15,2021 . The copyright holder for this preprint (which was not certified by peer review) is the author/funder, who has granted medRxiv a license to display the preprint in

It is made available under a CC-BY-NC-ND 4.0 International license.

\section{References}

1. Saeedi, P. et al. Global and regional diabetes prevalence estimates for 2019 and projections for 2030 and 2045: Results from the International Diabetes Federation Diabetes Atlas, 9(th) edition. Diabetes research and clinical practice 157, 107843 (2019).

2. Deshpande, A. D., Harris-Hayes, M. \& Schootman, M. Epidemiology of diabetes and diabetes-related complications. Physical therapy 88, 1254-1264 (2008).

3. Pociot, F. Type 1 diabetes genome-wide association studies: not to be lost in translation. Clinical \& translational immunology 6, e162 (2017).

4. Mahajan, A. et al. Fine-mapping type 2 diabetes loci to single-variant resolution using high-density imputation and islet-specific epigenome maps. Nature genetics 50, 15051513 (2018).

5. Vujkovic, M. et al. Discovery of 318 new risk loci for type 2 diabetes and related vascular outcomes among 1.4 million participants in a multi-ancestry meta-analysis. Nature genetics 52, 680-691 (2020).

6. Walter, K. et al. The UK10K project identifies rare variants in health and disease. Nature 526, 82-90 (2015).

7. Cohen, J. C., Boerwinkle, E., Mosley, T. H. \& Hobbs, H. H. Sequence variations in PCSK9, low LDL, and protection against coronary heart disease. The New England journal of medicine 354, (2006).

8. Akbari, P. et al. Sequencing of 640,000 exomes identifies GPR75 variants associated with protection from obesity. Science (New York, N.Y.) 373, (2021).

9. Abul-Husn, N. S. et al. A Protein-Truncating HSD17B13 Variant and Protection from Chronic Liver Disease. New England Journal of Medicine 378, (2018).

10. Wang, Q. et al. Rare variant contribution to human disease in 281,104 UK Biobank exomes. Nature (2021) doi:10.1038/s41586-021-03855-y.

11. Backman, J. D. et al. Exome sequencing and analysis of 454,787 UK Biobank participants. Nature (2021) doi:10.1038/s41586-021-04103-z.

12. Aimee M. Deaton et al. Gene-level analysis of rare variants in 379,066 whole exome sequences identifies an association of GIGYF1 loss of function with type 2 diabetes. Scientific Reports 11, (2021).

13. Karczewski, K. J. et al. The mutational constraint spectrum quantified from variation in 141,456 humans. Nature 581, (2020).

14. Naguro, I. et al. ASK3 responds to osmotic stress and regulates blood pressure by suppressing WNK1-SPAK/OSR1 signaling in the kidney. Nature communications $\mathbf{3}$, 1285 (2012).

15. Hattori, K., Naguro, I., Runchel, C. \& Ichijo, H. The roles of ASK family proteins in stress responses and diseases. Cell communication and signaling: CCS 7, 9 (2009).

16. Carithers, L. J. \& Moore, H. M. The Genotype-Tissue Expression (GTEx) Project. Biopreservation and biobanking 13, (2015).

17. Lawlor, N. et al. Single-cell transcriptomes identify human islet cell signatures and reveal cell-type-specific expression changes in type 2 diabetes. Genome research 27, 208-222 (2017).

18. Grün, D. et al. De Novo Prediction of Stem Cell Identity using Single-Cell Transcriptome Data. Cell stem cell 19, 266-277 (2016).

19. Muraro, M. J. et al. A Single-Cell Transcriptome Atlas of the Human Pancreas. Cell systems 3, 385-394.e3 (2016).

20. Baron, M. et al. A Single-Cell Transcriptomic Map of the Human and Mouse Pancreas Reveals Inter- and Intra-cell Population Structure. Cell systems 3, 346-360.e4 (2016).

21. Segerstolpe, $\AA$. et al. Single-Cell Transcriptome Profiling of Human Pancreatic Islets in Health and Type 2 Diabetes. Cell metabolism 24, 593-607 (2016).

22. Uhlén, M. et al. Proteomics. Tissue-based map of the human proteome. Science (New York, N.Y.) 347, (2015). 
medRxiv preprint doi: https://doi.org/10.1101/2021.11.14.21266328; this version posted November 15,2021 . The copyright holder for this preprint (which was not certified by peer review) is the author/funder, who has granted medRxiv a license to display the preprint in

It is made available under a CC-BY-NC-ND 4.0 International license

637

638

639

640

641

642

643

644

645

646

647

648

649

650

651

652

653

654

655

656

657

658

659

660

661

662

663

664

665

666

667

668

669

670

671

672

673

674

675

23. Mohan, V. et al. Comprehensive genomic analysis identifies pathogenic variants in maturity-onset diabetes of the young (MODY) patients in South India. BMC medical genetics 19, 22 (2018).

24. Lawrence Middleton et al. Gene-SCOUT: identifying genes with similar continuous trait fingerprints from phenome-wide association analyses. Nucleic Acids Res (in submission).

25. Vitsios, D. \& Petrovski, S. Mantis-ml: Disease-Agnostic Gene Prioritization from HighThroughput Genomic Screens by Stochastic Semi-supervised Learning. American journal of human genetics 106, 659-678 (2020).

26. Dwivedi, O. P. et al. Loss of $\mathrm{ZnT8}$ function protects against diabetes by enhanced insulin secretion. Nature genetics 51, 1596-1606 (2019).

27. Kleiner, S. et al. Mice harboring the human SLC30A8 R138X loss-of-function mutation have increased insulin secretory capacity. Proceedings of the National Academy of Sciences of the United States of America 115, E7642-E7649 (2018).

28. Ahlqvist, E. et al. Novel subgroups of adult-onset diabetes and their association with outcomes: a data-driven cluster analysis of six variables. The lancet. Diabetes \& endocrinology 6, 361-369 (2018).

29. Cnop, M. et al. Mechanisms of pancreatic beta-cell death in type 1 and type 2 diabetes: many differences, few similarities. Diabetes 54 Suppl 2, S97-107 (2005).

30. Surwit, R. S., Schneider, M. S. \& Feinglos, M. N. Stress and diabetes mellitus. Diabetes care 15, 1413-1422 (1992).

31. Chiodini, I. et al. Cortisol secretion in patients with type 2 diabetes: relationship with chronic complications. Diabetes care 30, 83-88 (2007).

32. Bycroft, C. et al. The UK Biobank resource with deep phenotyping and genomic data. Nature 562, 203-209 (2018).

33. Cingolani, P. et al. A program for annotating and predicting the effects of single nucleotide polymorphisms, SnpEff: SNPs in the genome of Drosophila melanogaster strain w1118; iso-2; iso-3. Fly 6, 80-92 (2012).

34. Traynelis, J. et al. Optimizing genomic medicine in epilepsy through a gene-customized approach to missense variant interpretation. Genome research 27, 1715-1729 (2017).

35. Ioannidis, N. M. et al. REVEL: An Ensemble Method for Predicting the Pathogenicity of Rare Missense Variants. American journal of human genetics 99, 877-885 (2016).

36. Manichaikul, A. et al. Robust relationship inference in genome-wide association studies. Bioinformatics 26, (2010).

37. Auton, A. et al. A global reference for human genetic variation. Nature vol. 526 (2015).

38. Stuart, T. et al. Comprehensive Integration of Single-Cell Data. Cell 177, (2019). 